\title{
An Analysis On The Dynamic Effect of Enterprise's Environmental Governance On Green Technology Innovation: New Explanation From The Perspective of Knowledge And Technology Transfer
}

Xianyou Pan ( $\sim$ pxybetter@163.com )

Shanghai University of Electric Power https://orcid.org/0000-0001-8314-025X

Xiongfeng Pan

Dalian University of Technology

Xianhua Wu

Shanghai Maritime University

Shucen Guo

Dalian University of Technology

\section{Research Article}

Keywords: Environmental Governance, Knowledge and Technology Transfer, Green Technology Innovation, Life Cycle, Dynamic Effect

Posted Date: September 7th, 2021

DOI: https://doi.org/10.21203/rs.3.rs-761429/v1

License: (9) This work is licensed under a Creative Commons Attribution 4.0 International License.

Read Full License 


\section{An analysis on the dynamic effect of enterprise's}

2 environmental governance on green technology innovation:

3 New explanation from the perspective of knowledge and

4 technology transfer

5

6

\section{Authors}

Co-author: Dr. Xianyou Pan, Lecturer of School of Economics and Management, Shanghai University of Electric Power, Shanghai, 200090, China. E-mail: pxybetter@163.com.

Co-author: Dr. Xiongfeng Pan, Professor of School of Economics and Management, Dalian University of Technology, Dalian, 116024, China. Email address: xiongfengpan@163.com.

Correspondence author: Dr. Xianhua Wu, Professor of School of Economics and Management, Shanghai Maritime University, Shanghai, 201306, China. Professor of Collaborative Innovation Center on Climate and Meteorological Disasters, Nanjing University of Information Science \& Technology, Nanjing, 210044, China.Tel.: +86 (21)38282475; E-mail: 185390@shmtu.edu.cn; wxhua_77@126.com.

Co-author: Shucen Guo, Ph.D candidate of School of Economics and Management, Dalian University of Technology, Dalian, 116024, China. Email:18340835228@163.com. 
An analysis on the dynamic effect of enterprise's environmental governance on green technology innovation: New explanation from the perspective of knowledge and technology transfer

Abstract: Environmental governance $(E G)$ and green technology innovation $(G T I)$ are important means to promote the construction of ecological civilization of all countries around the world. Past scholars focused on the impact of $E G$ on $G T I$ based on the static perspective usually, but ignored the impact of the dynamic development law of enterprises. This study differentiates, takes enterprise's life cycle stage as the breakthrough point, and analyzes the dynamic effect of $E G$ on $G T I$ at the first time. Further, considering the important of information interaction among different enterprise in the background of collaborative innovation, this study reveals the evolution trend of enterprise's knowledge and technology transfer $(K T T)$ in different life cycle stage, and explains the internal mechanism of the dynamic effect mentioned above. The theoretical model finds that for enterprises in different life cycle stage, the impact of $E G$ on $G T I$ depends on abatement cost and innovation compensation effect two aspects. The development of enterprise's $K T T$ helps to strengthen the incentive effect of $E G$ on $G T I$, thus causing the differentiated GTI effect among different enterprises under the restrict of EG. The empirical research results based on the micro data of Shanghai and Shenzheng A-share listed firms from 2013 to 2018 in China confirm the theoretical inference. $E G$ has a positive role in promoting $G T I$, however, compared with the 
enterprises in growth and mature stage, the positive innovation effect does not hold for the enterprises in recession stage. The statistical results show that the enterprise's KTT in growth and mature stage is significantly better than that of enterprises in recession. Moreover, the empirical analysis results confirm that enterprise's KTT have a positive moderating effect on the relationship between $E G$ and GTI. Combined with the above conclusions, this study puts forward several useful management implications for improving the designing of environmental governance system, optimizing the cooperation of $G T I$ and the $E G$ decision-making under the background of collaborative innovation.

Key words : Environmental Governance; Knowledge and Technology Transfer; Green Technology Innovation; Life Cycle; Dynamic Effect

\section{Introduction}

Due to the deviation between traditional economic model characterized by environment resource consumption and social needs of sustainable economic development, environmental governance $(E G)$ is one of the major direction for the further development of global economy (Zhang et al.2020). However, influenced the public nature of environmental pollution, market mechanisms are hard to fully correct the economic development direction (Tong and Ze,2021; Borsatto and Bazani,2020). $E G$ is the policies and measures formulated by government, which is employs price and quantity tools to adjust enterprise's environmental pollution, focus on the reducing of the dis-economy to the optimal level, and achieves the goal of sustainable development 
(Zhou et al.2021; Qiu et al.2021). Since then, the governments around the world have designed and implemented scientific and rational $E G$ to solve the problem of environmental pollution (Jiang et al.2018; Dong et al.2020). For example,Paris Agreement signed the Paris Climate Conference in 2015 and regulated the reduction of greenhouse gas emissions by all parties. In June 2018, the State Council of China issued the "blue sky defensive war", which aims at the promoting of energy conservation and emissions reduction in the key sectors.

Different from the $E G$ aimed at the terminal environmental governance, green technology innovation $(G T I)$ is an important starting point for the enterprises to win the battle of pollution control and ecological civilization construction (Wang et al.2021). Therefore, a series of green technological strategies for reducing pollution that produced by traditional technologies must be respond to social need (CubillosGonzalez and Cardoso,2020). According to Porter and Linde (1995), GTI are induced by the strict environmental governance measures, in order to offset compliance costs. In detail, EG significantly improves enterprise's “green" consciousness, and increases the enterprise's abatement cost thus encouraging them to invest in GTI (Song et al.2020). Two basis theories explain the effect of $E G$ on GTI. GTI of enterprises is restricted by $E G$, which is called the "restriction hypothesis" (Gollop and Roberts,1983). Based on the technology innovation patent data of listed companies, industries and regions, scholars used panel econometric model to verify and support the inhibition effect of $E G$ on GTI (Feng et al.2018; Hu and Liu,2019; Qiu et al.2020; Li et al.2020). Influenced by the "organizational failure" or "market failure" (Amber et al.2010), Porter (1991) 
and Porter and Linde (1995) provided the opposing view which argues that $E G$ increases costs in the short term, but promotes enterprises to carry out GTI in the long term, thereby reducing abatement costs and ultimately enabling them to be more competitive. Since then, many scholars took the provincial, listed companies, high pollution industry and other relevant data as research object, used fixed effect model, questionnaire survey, structural equation model and panel measurement model to test the existence of "innovation compensation" effect between $E G$ and GTI (Cai et al.2020; Raza,2020; Qiu et al.2020; Lee et al.2010; Wang et al.2020; Li et al.2019).

Further, faced with the constraints of $E G$, heterogeneous enterprises hardly to follow the coincident GTI path influenced by the differentiated conditions such as internal resource endowment, dynamic capacities and external policy environment (Cai et al.2020; Luo et al.2021). That is, fully considering the uncertainty and heterogeneity conditions, not all of the enterprises achieve innovation compensation effect faced with the constraints of $E G$ (Borsatto and Bazani,2020; Daddi et al.2010; Chakraborty and Chaterjee,2017). Since then, employed panel econometric model, spatial regression model and so on, several scholars pointed out that the impact of $E G$ on $G T I$ is nonlinear and affected by the environmental governance type, pollution intensity, technology innovation process, economic scale and so on (Dong et al,2012; Pan et al.2020; Song et al.2020; Guo et al.2018; Liu and Gong,2018).

Different from the existing researches focus on the nonlinear relationship between $E G$ and $G T I$, this study points out that enterprises are difficult to achieve effective $G T I$ under the constraints of $E G$ simply relying on the internal resources. According to the 
view of knowledge heterogeneity provided by Schulze and Brojerdi (2012), this study believes that the impact of $E G$ on $G T I$ is influenced by the knowledge and technology transfer $(K T T)$. There are many literature have studied the relationship between external knowledge heterogeneity and technology innovation, but the conclusions are different. Some scholars proposed that enterprises absorb and integrate the rich and novel heterogeneous knowledge from the outside, effectively make up for the defects of internal knowledge resources and promote collaborative innovation (Srivastava and Gnyawal,2017). Moreover, external heterogeneous knowledge reduces the core rigidity and path dependence of $G T I$, and promotes enterprises to continuously reconstructs knowledge resources and achieves green innovative achievements (Alexander and Knippenberg,2017); However, parts of scholars pointed out that heterogeneous knowledge not only easily leads to internal cognitive conflict, but also increases the management cost of knowledge transaction, which is not conducive for enterprises to carry out GTI (De-Leeuw et al.2014). This study argues that the reason for the above contradictory conclusions is that most of the existing studies are based on the static perspective, ignored the impact of the dynamic development law of enterprises. For example, Ballard (2009) believed that heterogeneity is essentially an interactive relationship, and its value effect is different at different stages of the development stage. Looking at the existing literature, most scholars discussed the impact of $E G$ on GTI based on the sample of regional and industrial levels (Johnstone et al.2010; Villegas-Palacio and Coria,2010; Hattori,2017; Cai and Li,2018), which can not directly reflect the enterprise's $G T I$ under the pressure of $E G$. Few literature focused on 
the enterprise level (Popp,2003; Klemetsen et al.2018; Ramanathan et al.2018), but most of them took the developed countries as research objects. However, there is a substantial gap of industrial modernization and $E G$ system between China and developed countries (Cai et al.2002). In addition, the heterogeneous effect of $E G$ on GTI has not been explored, thus making the practical significance of the research results needs to be improved. Knowledge-based theory holds that external heterogeneous knowledge fills in the knowledge gap of enterprises, while internal knowledge diversification will affect the meaning construction and interpretation results (Oerlemans et al.2013;Secchi et al.2016). Previous studies have shown that knowledge diversification expands its own knowledge base, explores a variety of innovative combinations with the acquired external heterogeneous knowledge, and effectively breaks the thinking bottleneck. However, there is still no relevant research takes the KTT as the starting point, explain the formation mechanism of the dynamic effect of $E G$ on $G T I$ from the perspective of life cycle stage.

Compared with the existing researches, the possible contributions of this study include the following two aspects: First, although existing studies have carried out specific analysis of the effects of $E G$ on $G T I$ on industry and regional levels, seldom use data at the micro-level. Considering enterprises as the main body of $E G$ and GTI, analyzing the effect of $E G$ on $G T I$ from the micro level of enterprises is a complement to existing researches; Second, the KTT of enterprises in different life cycle stages is an important factor to regulate the GTI under the constraints of $E G$. Existing research does not discuss the non-linear relationship between $E G$ and $G T I$ from this perspective. This 
study dynamically analyzes the impact of $E G$ on enterprise's $G T I$ in different life cycle stages, and expounds the formation mechanism of dynamic effect mentioned above from the perspective of $K T T$ at the first time.

\section{Theoretical analysis and research hypothesis}

According to the research of Montero (2002), this study considers a model which includes two profit-maximizing firms. Firm $i$ produces $q_{i}$ at cost $c$, and the inverse demand function is $P=P(Q)$, where $P$ is the market price and $Q=q_{1}+q_{2}$ is industry output. In the absence of $E G$, enterprises produce $q_{i}$ units of emission, and the cost of $q_{i}$ is $C_{i}\left(q_{i}-e_{i}\right), e_{i}$ is the final emissions after abatement. As usual, $C^{\prime}>0$ and $C ">0$.

The aims of $E G$ is to control emissions at $\bar{e}=e_{1}+e_{2}$. Under the restriction of $E G$, firm $i$ improve its technology of abatement by investing in GTI. Referring to the setting of Montero (2002), if it invests $K_{i}$, abatement costs are expected to be reduced from $\frac{r^{2}}{2}$ to $\frac{k r^{2}}{2}$, where $r_{i}=q_{i}-e_{i}$. According to the production function:

$$
k_{i}=f_{i}\left(K_{i}, s\right)
$$

where, $f(0)=1, f(\infty)>0, f^{\prime}<0, f^{\prime \prime}>0$ and $f^{\prime \prime \prime}>0$.

Assumes that the difference between firm 1 and firm 2 is that enterprise 2 does not carry out $G T I$ under the restrict of $E G$, but bears the penalty $\operatorname{cost} A$ due to violation of $E G$. Further, based on the $K T T$, the investment of $G T I$ changes form $\frac{K^{2}}{2} \operatorname{to}(1-s) \frac{K^{2}}{2} \cdot s$ is the parameter of firm's KTT. Then the profit functions of firm 1 and firm 2 can be expressed as:

$$
\begin{aligned}
& \pi_{1}=\left[a-b\left(q_{1}+q_{2}\right)-c\right] q_{1}-(1-s)\left(\frac{k r^{2}}{2}+\frac{K^{2}}{2}\right) \\
& \pi_{2}=\left[a-b\left(q_{1}+q_{2}\right)-c\right] q_{2}-A
\end{aligned}
$$


176 where, $m$ is the pollutant generation coefficient, which represents the proportion of the

177 firm's pollutant production in the product output. Therefore, $m q_{1}$ represents the 178 pollutant production of firm 1, and $\bar{e}$ represents the firm's maximum pollutant emission 179 specified by the government. Therefore, the economic meaning of equation (3) is that 180 the emission of firm 1 is equal to the scale which regulated by the government $E G$.

181 According to the first-order condition of profit maximization under constraint 182 conditions, obtain partial derivatives of output $q_{1}$ and $q_{2}$, emission reduction $r$ and Lagrange multiplier $\lambda$ :

$$
\frac{\partial \pi_{1}}{\partial \lambda}=m q_{1}-r-\bar{e}=0
$$

Based on the equation (6), obtain $\lambda=k r$ and substitute to equation (4)

$$
\frac{\partial \pi_{1}}{\partial q_{1}}=a-2 b q_{1}-b q_{2}-c-k r m=0
$$

Based on equation (5) and (8), obtain $q_{1}$ and $q_{2}$ :

$$
q_{1}=\frac{a-2 k r m-c}{3 b}
$$

195 obtain:

Substitute $q_{1}$ and $q_{2}$ to equation (1) and (2), the profit of firms are subtracted to obtain:

$$
\Delta \pi=\pi_{1}-\pi_{2}=A-\frac{(a+k r m-c) k r m}{3 b}-(1-s) \frac{k r^{2}}{2}-(1-s) \frac{K^{2}}{2}
$$


where, $\Delta \pi$ is determined by the government's penalty cost $A$, firm's $G T I$ capability $k$, abatement $\operatorname{costs} \frac{k r^{2}}{2}, G T I \operatorname{costs} \frac{K^{2}}{2}$ and KTT parameter. It means that when the marginal profit greater than zero after the introduction of $E G$, enterprises will have enough incentive to carry out $G T I$.

Based on the equation (11), abatement costs $\frac{k r^{2}}{2}$ represents the investment in purchasing of clean equipment and hiring technical staff, which can be regarded as the firm's "following the cost effect" under the constraints of governance environmental regulation (Hu and Liu,2019). If the products produced by the firms have low market demand elasticity and maintain a certain monopoly position, $E G$ cost can be transferred to consumers by raising product price and stimulates firms to carry out GTI by obtaining excess monopoly profits (Hattori, 2017). Moreover, with the adjustment of GTI strategy, polluting enterprises faced with the constrains of $E G$ gradually withdraw from the market. The technical barriers constructed by technological monopoly position become the monopoly profit source and an incentives mechanism for the green enterprises to carry out GTI (Melitz,2003). Finally, faced with more stringent EG, adopting GTI improves firm's clean product abilities and reduces the marginal abatement cost on the basis of keeping the original output unchanged, thus stimulating firm's GTI intentions (Xia et al.,2021). Therefore, this study puts forward the Hypothesis 1:

H1: $E G$ has a positive effect on $G T I$.

$E G$ is difficult to achieve by firms lonely, which needs multi-agent coordination and agglomeration of innovation elements (Schubert and Gupta, 2013). In order to meet the social environmental need, enterprises combine related topics through various forms 
219 of collaborative innovation, expand the innovation network, absorb innovation 220 elements, form technology collaboration, tackle common problems in the process of $221 E G$, and reduce the cost of abatement costs $\frac{k r^{2}}{2}$ (Kim and Sim, 2016; Zhang et al.,2020). 222 Under the pressure of $E G, G T I$ in an environmental management requires new ways of 223 thinking and applies it throughout $E G$ (OECD, 2012). It is a kind of creative ideas 224 generated form individuals or staff, and occur with support from R\&D and through 225 knowledge and technology transfer (Cubillos-Gonzalez and Cardoso, 2020; Gu et 226 al.,2021). In the process mentioned above, KTT is helpful to expand the scope of 227 enterprise's search resources, help enterprises identify and obtain the technology 228 required for $E G$, realize the coordination of external and internal technology sources, 229 promote the evolution of GTI ability, and quickly reduce the cost of GTI denoted by $\frac{K^{2}}{2}$ 230 (Liu, 2019). Therefore, this study puts forward the Hypothesis 2:

H2: The KTT positive moderate the impact of $E G$ on $G T I$.

232

\section{Model and data}

\subsection{The benchmark regression model}

The main concern of this study is whether $E G$ can promote GTI. Due to the measurement of GTI is the number of applications for environmental patents, so, this paper constructs the following panel counting model.

$$
G T I_{i, t}=\alpha_{0}+\alpha_{1} E G_{i, t}+\sum_{j=1}^{8} a_{j} X_{j, i, t}+v_{i}+\varepsilon_{i, t}
$$

where, the subscripts $i$ and $t$ denotes the firm and year, respectively. GTI indicates the level of firm's green technology innovation, $E G$ represents the environmental 
governance. $X$ represents the control variables, mainly includes the age of enterprises,

241 the current ratio, the return on assets, the turnover rate of assets and the enterprise

242 ownership structure. $\varepsilon$ is a random error term, $v_{i}$ is individual effect, and $\alpha_{i}$ are all

243 parameters to be evaluated. In order to alleviate the endogeneous problem caused by

244 the relationship between $E G$ and $G T I$, this study adopts the fixed effect model to allow

$245 v_{i}$ to be correlated with the explanatory variable(Cai et al.,2020).

\subsection{The moderating effect model}

In addition to the direct impact of the $E G$ on the $G T I, K T T$ also indirectly moderate

the relationship between the $E G$ and the GTI. The cross-term method of the KTT and $E G$ is introduced to investigate the moderating effect of $K T T$, and the corresponding model is presented:

$$
G T I_{i, t}=\alpha_{0}+\alpha_{1} E G_{i, t}+\alpha_{2} E G_{i, t} * K T T_{i, t}+\sum_{j=1}^{8} a_{j} X_{j, i, t}+v_{i}+\varepsilon_{i, t}
$$

where, $a_{1}$ and $a_{2}$ reflect the direct and indirect effects of the $E G$ on the $G T I$, respectively.

\subsection{Data sources and variables description}

This study collects all listed firms of Shanghai and Shenzhen A-shares in China from 2013 to 2018. Among them, GTI patents and KTT are collected from the State Intellectual Property Office (SIPO) of the People's Republic of China; EG is obtained mainly through the annual reports or social responsibility reports of listed firms; Other control variables were collected from the CSMAR Data Service Center and the Wind Financial Database. This study excludes $S T$ and ${ }^{*} S T$ firms with abnormal financial status and with missing data. Finally, 795 observation samples were obtained. 
Winsorize treatment was performed on the $1 \%$ level of all continuous variables. Table

2621 shows the description analysis results.

263

\subsubsection{Dependent variables}

Environmental patent applications were used here as a measure of GTI. In order to improve the core of competitiveness of enterprises, they used to apply for patents to keep technological advantages, so as to obtain greater profits. In addition, the authorization of the invention patents through the strict examination of the patent examiner, they has a stronger practicability, novelty, and creativity (Klemetsen et al.2018). Therefore, GTI is measured by the patent applications for environmental inventions. Combined with the IPC classification issued by the World Intellectual Property Organization (WIPO), this paper took alternative energy production, waste management, energy conservation as the specific items, matched the number of environmental patent applications filed by each listed firms in the SIPO database.

\subsubsection{Independent variables}

Past researches usually used the different indicators, such as the rectification of violations and administrative penalties for environmental protection as the indicator of $E G$. According to the research of Song and Wang (2020), this study takes pollution treatment investment of enterprises as an indicator of $E G$, it refers to the capital used to form fixed assets in the process of pollution treatment, which includes the investment in environmental infrastructure construction, new and old pollution sources control projects and environmental protection investment projects. 
significantly improved with their rapid development, while reduced when enterprises enter the stage of recession (Balasubramanian and Lee, 2008).

The return on assets is the percentage of a company's profit divided by its net assets, which reflects the ability to obtain income based on its own assets (Xin et al.,2010). The growth of return on assets can enhance the financial support for green investment and promote $G T I$.

The Current ratio is the ratio of current assets to current liabilities, which reflects the ability of current assets to be realized and used to repay liabilities. The higher the value is, the stronger the short-term solvency is, which is helpful to increase GTI investment, otherwise it is weak.

Ownership structure: The main reason for the lack of motivation or efficiency of GTI in state-owned enterprises is that there is a serious principal-agent problem, which can not effectively supervise and motivate the operators (Boubakri et al.,2013). However, state-owned enterprises have obvious advantages over private enterprises in obtaining innovation resources (Wang et al.,2017).

Asset turnover rate: it is an index to evaluate the efficiency of a company's asset operation and reflects the utilization efficiency of the company's assets (Ang, 2000). The higher the asset turnover rate of an enterprise, the stronger its sales ability, the higher the efficiency of asset utilization, and the lower the principal-agent cost.

\subsubsection{Moderating variables}

Innovations are creative ideas generated from individuals or staff, and occur with support from R\&D and through KTT (Muduli et al.,2013). Drivers for GTI include 
strong business networks, seeking to build competitive advantage, R\&D organizational support, cost savings, subsidies and tax cuts, compliance with regulations and customer demand (Vasilenko and Arbaciauskas,2012). KTT reflects the information interaction among enterprises by means of technology transfer and patent disclosure (Claro et al.,2006). According to the research of Hastbacka(2004), West and Gallagher (2006), this study measures the KTT by the enterprises "Whether there is a technology disclosure/transfer" and "whether there is a patent disclosure /transfer", where "yes" is 1 and "no" is 0.

\section{Results and discussion}

The value of VIF is much lower than 10, and indicates that there was no problem with multicollinearity. The results of correlation analysis listed in the Table 2 shows that the correlation coefficient of each variable is less than 0.7 .

\subsection{The benchmark effect of EG on GTI}

Based on the equation (12) and employed the static fixed effect model, the benchmark effect of $E G$ on $G T I$ is tested. As can be observed from the results listed in the second column of the Table 3, the coefficient of $E G$ is 0.05 and passes the significance test at $1 \%$ level. In order to guarantee the reliability of the empirical results, each control variables are added step by step. As shown in columns from (3) to (7) of 
Table 3, the regression coefficients of $E G$ varied from 0.077 to 0.094 and pass the significance test at $1 \%$ level. According to the the theory of institutional economy, $E G$ has the function of influencing and constraining organizational behavior (Li et al. 2017). Lower $E G$ is hardly to affect the enterprise production and management activities and the decision-makers in the system pressure (Chen and Zhang, 2017). With the improvement of regulator standards, the production suspension and production restriction directly affect the decisions of GTI (Wang and Li, 2009; Guo and Licheng, 2020).

\subsection{Endogenous recognition and system generalized method of moments (System-GMM)}

The impact of EG on GTI may be endogenous, which leads to inconsistent estimates. There are two main reasons for this: (1) Simultaneous equations endogenous: the enterprises who investment in $E G$ will pay more attention on GTI. However, GTI further reduces the enterprise's pollution control investment, which leads to nonexogenous of $E G$. The endogenous of simultaneous equations caused by the interaction can be eliminated by substituting the explanatory variables with their lag term. (2)

Missing variable endogenous: even though the control variables are considered as comprehensively as possible, there are many other factors related to the GTI can not be expressed quantitatively, such as entrepreneurship, development strategy, etc. The solution is to add the one-period lag term of $G T I$ as an explanatory variable.

According to the research of Arellano and Bover (1995) and Blundell and Bond (1998), the System-GMM model is employed to estimate the results. As shown in the Table 4, the regression coefficients of L.EG and L.GTI is 0.057 and 0.616 , respectively, 
both of them passes the significance test at $1 \%$ level. It must be noted that the above conclusion is based on the premise that GMM estimates are effective. The AR (1), AR (2) and Sagan test statistics reported in Table 4, which proved that the tool variables selected in system-GMM estimation are valid.

\section{Insert Table 3 here}

\subsection{Analysis of the heterogeneity of enterprise's life cycle}

As a highly uncertain and risky economic behavior, GTI has a vital impact on its own heterogeneous resources and unique capabilities. In reality, different enterprises consider internal and external conditions comprehensively, and will adopt a differentiated behavior-oriented mode to deal with environmental pollution problems, it means that promoting the efficient matching between GTI decisions and capability is the key link under the constraints of $E G$ (Luo et al.2021). Thus, from the perspective of enterprise life cycle stage, this study examines the heterogeneity effect of $E G$ on GTI.

Using different enterprise life cycle stage division criteria will get different results. The mainstream method of classification mainly including comprehensive scoring and cash flow classification (Anthony and Ramesh,1992). Compared to the comprehensive scoring method, the cash flow-based stage division method effectively avoids the possible linear relationship among indicators, and overcomes the bias caused by the enterprise managers earnings manipulation (Dickkinson,2011). Therefore, this study uses the characteristics of enterprise cash flow to divide the life cycle stage. Considering that the sample data in this study are listed firms and have basically passed the initial 
stage. According to the criteria proposed by Dickkinson,(2011), the sample enterprises are divided into three stages: growth, mature and recession.

The heterogeneity regression results are shown in the Table 4. Compared with the regression coefficients of $E G$ in different life cycle stages, it can be found that the effect of $E G$ on $G T I$ in mature stage is the most significant (0.089), it is relatively weak in growth stage (0.053), while, the effect is insignificant in the recession period. The view of natural resource-based is helpful to explain the relationship between firms' life cycle state and the GTI under the restrict of $E G$ (Hart, 1995). Firms invest in environmental strategies under the pressure of $E G$, such as $G T I$, will be able to keep economic growth (Ashraf et al.,2018). Firms want to obtain greater advantage and be motivated by future benefits, are more likely to invest in GTI (Ashraf et al.,2018). In addition, firms that consider the natural environment are better able to utilize their resources and capabilities when adopting GTI (Adeel et al.,2020).

\subsection{Analysis of the moderating effect of KTT on the relationship between EG and GTI}

Insert Table 4 here

enterprises in different life cycles. Combined with theoretical analysis, KTT has a significant moderating effect on the relationship between $E G$ and GTI. In order to verify the above inference, we carries out the quantitative analysis on the life cycle difference and its moderating effect of $K T T$.

According to the research of Gao et al.(2011), we test the difference of enterprise's 
$K T T$ in different life cycle stage by one way test of variance. The $p$ value of Bartlett test is less than 0.05 , which means that $F$ test is significant at $5 \%$ level. That is, the KTT of enterprises in different life cycle stages is different. Further, it can be seen from the Figure 1, compared with the enterprises in the recession period, the KTT scale of enterprises in the mature and growth periods is larger.

As shown in the Table 5, the coefficient of $E G^{*} K T T$ is positive and pass the significance test at the $1 \%$ level, it means that the KTT has a positive moderating effect on the relationship between $E G$ and $G T I$, thus validating the rational of hypothesis $\mathrm{H} 2$, which posits that compared with the enterprises with lower KTT scale, the promotion effect of $E G$ on the enterprise's $G T I$ with higher $K T T$ scale is more significant. This conclusion further confirms the inference in this study that KTT is an important determinant of the differentiated impact of $E G$ on $G T I$ in different life cycle stages. In addition, the estimation results based on System-GMM show the results are robust. First, growth and mature firms have stronger KTT networks which promote the enterprises to improve GTI abilities through adopting advanced technology and equipment (Tsai and Ghoshal, 1998). Moreover, stronger KTT capabilities facilitates the development of GTI and achieves higher GTI performance (Adeel et al.2020). Second, KTT enhances promotes enterprises to capture new information and improve their GTI efficiency. Therefore, stronger $K T T$ abilities facilitate assimilation of knowledge from external sources, and it is useful to reduce the abatement costs and achieve higher GTI efficiency under the constraint of $E G$ (Ketata et al.2014). 


\section{Conclusions and policy recommendations}

Based on the micro enterprises of pollution treatment investment and green technology innovation patent applications of Shanghai and Shenzhen A-share listed firms in China from 2013 to 2018, this study employees static fixed effect model and system-GMM two model to dynamically analyses the impact of $E G$ on $G T I$ from the perspective of enterprise's life cycle stage. Further, this study reveals the importance of information interaction for reducing abatement costs and improving GTI performance, starting from the view of $K T T$, explains the internal mechanism that $E G$ has different effects on GTI of enterprises in different life cycle stage.

(1) The impact of EG on $G T I$ depends on environmental governance cost and innovation compensation effect two aspects. In general, $E G$ has a positive effect on $G T I$, but it has significant differentiated impact on GTI of enterprises in different life cycle. Compared with the enterprises in growth and mature stage, the positive effect mentioned above does not hold for the enterprises in recession stage.

(2) Based on the division of enterprise life cycle stage, it is found that the KTT shows the trend of rising and decreasing with the development of enterprise. Further, $K T T$ has a positive moderating effect on the relationship between $E G$ and $G T I$, thus making the impact of $E G$ on $G T I$ is significant is both of the enterprises in growth and mature stage, but it is insignificant of enterprises in recession stage. Based on our findings, we propose the following policy recommendations:

(1) Government agencies should appropriately strengthen the implementation of 
$E G$ policies, punish enterprises with negative environmental attitude, so as to encourage polluting enterprises to carry out GTI. However, the government should not blindly improves the regulation intensity, clarify the dynamic characteristics of the impact of $E G$ on enterprise's $G T I$, fully considers the changes in the development stage of local enterprises, timely adjusts the regulation mode and strength, guides parts of green enterprises to obtain cost advantage through tax subsidies.

(2) Faced with the increasing of investment in pollution control, enterprises should fully realize the importance of $K T T$ in the collaborative innovation environment, share advanced environmental protection knowledge and innovative information resources, form a unified collaborative system of $E G$ and $G T I$, so as to avoid the uncertainty brought by $E G$ and improve the performance of GTI. Moreover, enterprises should establish a cost sharing mechanism, reduce the risk of collaborative innovation, promote the formation of long-term cooperative relationship, make up for the lack of internal resources.

(3) Enterprise managers should make straighten up and pay attention to the current stage of enterprise's development, systematically comb and summarize the enterprise's GTI strategies and the implementation of $E G$ measures according to the life cycle stage characteristics. At the same time, equipping talents with market innovation ability, actively obtaining external support and seeking partners, thus strengthening the profitability of enterprises through $K T T$. 
Ethics approval is not required for this research.

457

458

459

460

461

462

\section{Consent to Participate and Publish}

The manuscript is approved by all authors for publication and is an original research that has not been published previously, and not under consideration for publication elsewhere, in whole or in part. All the authors listed have approved the enclosed manuscript.

\section{Authors Contributions}

Xianhua Wu and Xiongfeng Pan: Conceptualization, Methodology, and Supervision. Xianyou Pan and Shucen Guo: Writing- Reviewing and Editing.

\section{Funding}

This work was supported by: the National Natural Science Foundation of China (Grant Nos. 71734001); the National Social Science Foundation Project (Grant Nos. 17BGL266; 18ZDA052); Program for Liaoning innovative talents in University (Grant Nos. WR2019003); Liaoning Provincial Economic and Social Development Project (Grant Nos. 2021lslybkt-008); Fundamental Research Funds of Dalian University of Technology (Grant Nos. DUT21RW209).

\section{Competing Interests}

There is no conflict of interest with this manuscript.

\section{Availability of data and materials}


The datasets used or analysed during the current study are available from the corresponding author on reasonable request.

\section{References}

Acemoglu, D., Aghion, P., Burssztyn L., and Hemous D. 2012. The Environment and Directed Technical Change. American Economic Review. 102(1):131-166

Adeel, T., Youser, F.B., Umar, S., Waqas, T., Kamal, B. 2020. Linking firms’ life cycle, capabilities, and green innovation. Journal of Manufacturing Technology Management. 31(2):284-305

Alexander, L and Knippenberg, D.V. 2017. Teams in Pursuit of Radical Innovation: A Goal Orientation Perspective. IEEE Engineering Management Review, 45(1):105-120

Ambec, S., Cohen, M.A., Elgie, S., Lanonie, P. 2010. The porter hypothesis at 20: can environmental regulation enhance innovation and competitiveness? Review of Environmental Economics and Policy. 7(1):2-22

Ang, J.S., Cole, R.A., Lin, J.W. 2000. Agency costs and ownership structure. The Journal of Finance, $55(1): 81-106$

Anthony J. H., Ramesh K. 1992. Association between Accounting Performance Measures and Stock Prices: A Test of the Life Cycle Hypothesis. Journal of Accounting and Economics, 15:203227.

Arellano, M. and Bover, O. 1995, Another Look at the Instrumental Variables Estimation of Error Component Models, Journal of Econometrics, 68:29-51

Ashraf, N., Comyns, B., Arain, G.A., and Bhatti, Z.A. 2018. The roles of network embeddedness, market incentives, and slace resources in the adoption of clean technologies by firms in 

developing countries. Climate Policy,19(2):1-15

Balasubramanian, N and Lee, J. 2008. Firm age and innovation. Industrial and Corporate Change, 17(5):1019-1047

Balland, P.A. 2009. Proximity and the Evolution of Collaboration Networks: Evidence from R\&D Projects within the GNSS Industry. Papers in Evolutionary Economic Geography. 46(6):741756

Bai, Y., Song, S.Y., Jiao, J.L., et al. 2020. The impacts of government R\&D subsidies on green innovation: Evidence from Chinese energy-intensive firms. Journal of Cleaner Production. 233:819-829

Blundell, R. and Bond, S. 1998, Initial Conditions and Moment Restrictions in Dynamic Panel Data Models, Journal of Econometrics, 87:115-143

Borsatto, J.M.L.S and Bazani, C.L. 2020. Green innovation and environmental regulations: a systematic review of international academic works. Environmental Science and Pollution Research. Doi:10.1007/s11356-020- 11379-7

Boubakri, N., Gosset, J., Saffar, W. 2013. The role of state and foreign owners in corporate risktaking: Evidence from Privatization. Journal of Finance and Economics, 108(3):641-658

Cai, W.G., Li, G.P. 2018. The drivers of eco-innovation and its impact on performance: evidence from China. Journal of Cleaner Production. 176:110-118

Cai, X., Zhu, B.Z., Zhang, H.J., et al. 2020. Can direct environmental regulation promote green technology innovation in heavily pollution industries? Evidence from Chinese listed companies. Science of the Total Environment, 746(1):140810

Chakraborty P., Chaterjee C.2017. Does environmental regulation indirectly induce upstream 
Claro, D., Claro, P., Hagelaar, G. 2006. Coordinating collaborative joint efforts with suppliers: the effect of trust, transaction specific investment and information network in the Dutch flower industry. Supply Chain Management. 11:216-224

Cubillos-Gonzalez, R.A., Cardoso, G.T. 2020. Clean technology transfer and innovation in social housing production in Brazil and Colombia. A framework from a systematic review. Sustainability, 12(4):1335

Daddi T., Testa, F., Iraldo F. 2010. A Cluster-based approach as an effective way to implement the ECAP: Evidence from some good practice. Local Environment, 15(1):73-82

Dickinson V. Cash flow patterns as a proxy for firm life cycle. Account Review. 2011,86(6), 19691994.

De-Leeuw, T., Lokshin, B., Duysters, G. 2014. Returns to Alliance Portfolio Diversity: the Relative Effects of Partner Diversity on Firm's Innovative Performance and Productivity. Journal of Business Research. 67(9):1839-1849

Dong, Z.Q., He, Y.D., Wang, H., et al. 2020. Is there a ripple effect in environmental regulation in China? Evidence from the local-neighborhood green technology innovation perspective. Ecological Indicators, 118:106773

Feng Z.J., Zeng B., Ming Q. 2018. Environmental regulation, two-way foreign direct investment, and green innovation efficiency in China's manufacturing industry. International Journal of Environmental Research and Public Health,15(10):2292

Gao, S., Zhuang, H., Wang, Y. 2011. Operational characteristics of each life cycle stage in technology-based small and middle-sized enterprises. Science Research Management, 
542 Gollop, E.M., Roberts, M.J. 1983. Environmental regulations and productivity growth: the case of fossil-fueled electric power generation. Journal of Political Economy,91(4):654-674

Gu, G.X., Wang, Z., Wu, L.Y. 2021. Carbon emission reductions under global low-carbon technology transfer and its policy mix with R\&D improvement. Energy. 216:119300

Guo Y.Y., Xia X.N., Zhang S. et al. 2018. Environmental regulations, governmental R\&D funding and green technology innovation: evidence from China provincial data.

Hart, S.L. 1995. A natural-resource-based view of the firm. Academy of Management Review,20(4):986-1014

Hastbacka, M. 2004. Open Innovation: what is mine is Mine, What is your could be Mine, too?,

Hattori, K. 2017. Optimal combination of innovation and environmental policies under technology

$$
\text { licensing. Economic Modelling, 64:601-609 }
$$

Hu S.M., Liu S.L.2019.Do the coupling effects of environmental regulation and R\&D subsidies work in the development of green innovation? Empirical evidence from China. Clean Technologies and Environmental Policy, 21(9):1739-1749

Jiang, Z.Y., Wang, Z.J., and Li, Z.B. 2018. The effect of mandatory environmental regulation on innovation performance: Evidence from China. Journal of Cleaner Production. 203:482-491

Johnstone, N., Hascic, I., Popp, D. 2010. Renewable energy policies and technological innovation: evidence based on patent counts. Environmental \& Resource Economics. 45(1):133-155

Ketata, I., Sofka, W., Grimpe,C. 2014. The role of internal capabilities and firms' environment for sustainable innovation: evidence from Germany. R\&D Management, 45(1):60-75 
564 Kim, B., Sim, J.E. 2016. Supply chain coordination and consumer awareness for pollution reduction. Sustainability,8(4):365

Lee C.W. 2020. The effect of environmental regulation on green technology innovation through supply chain integration. International Journal of Sustainable Economy,2(1):92-112

Li, D., Zheng, M., Cao, C., et al., 2017. The impact of legitimacy pressure and corporate profitability on green innovation: evidence from China top 100. Journal of Cleaner Production. 141, 41 -

Li D.Y., Tang F., Jiang J.L. 2019. Does environmental management system foster corporate green foreign direct investment on green innovation across different regions in China. Science of the 
587

588

Melitz, M. 2003. The impact of trade of intra-industry re-allocations and aggregate industry productivity. Econometrica. 71(6):1695-1725

Montero, J.P. 2002. Permits, standards, and technology innovation. Journal of Environmental Economics and Management, 44(1):23-44

Muduli, K.; Govindan, K.; Barve, A.; Geng, Y. Barriers to green supply chain management in Indian mining industries: A graph theoretic approach. Journal of Cleaner Production. 2013, 47, 335344.

Klemetsen, M.E., Bye, B., Raknerud, A. 2018. Can direct regulations spur innovation in environmental technologies? A study on firm-level patenting. Scandinavian Journal of Economics, 120(2):338-371

Oerlemans, L.A.G., Knoben, J., Pretorius, M.W. 2013. Alliance Portfolio Diversity, Radicaland Incremental Innovation: The Moderating Rola of Technology Management. Technovation. 33(6-7):234-246

Organization for economic cooperation and development (OECD). The future of eco-innovations: the role of business models in green transformation. OECD: Paris, France, 2012.

Pan X., Cheng W.Y., Gao Y.N et al. 2020. Is environmental regulation effective in promoting the quantity and quality of green innovation. Environmental Science and Pollution Research,28(5):6232-6241

Popp, D. 2003. Pollution control innovations and the Clean Air Act of 1990. Journal of Policy Analysis and Management. 22(4):641-660

Porter, M.E. 1991. America's green strategy. Scientific American. 264,168 
608

609

610

611

612

613

614

615

616

617

618

Porter, M.E., Van der Linder, C. 1995. Toward a new conception of the environmentalcompetitiveness relationship. Journal of Economic Perspectives. 9(4):97-118

Qiu L., Hu D., Wang Y. 2020. How do firms achieve sustainability through green innovation under external pressures of environmental regulation and market turbulence?. Business Strategy and the Environment, 29(6):2695-2714

Qiu, S.L., Wang, Z.L., Geng, S.S. How do environmental regulation and foreign investment behavior affect green productivity growth in the industrial sector? An empirical test based on Chinese provincial panel data. Journal of Environmental Management. 287:112282

Ramanathan, R., Ramanathan, U., Bentley, Y. 2018. The debate on flexibility of environmental regulations, innovation capabilities and financial performance-a novel use of DEA. Omega,75:131-138

Raza Z. 2020. Effects of regulation-driven green innovations on short sea shipping's environmental and economic performance. Transportation Research Part D-Transport and Environment, $84: 102340$

Schubert, S., Gupta, J. 2013. Comparing global coordination mechanism on energy, environment, and water. Ecology and Society, 18(2):22

Schulze, A., Brojerdi, G.J.C. 2012. The effect of the distance between partners knowledge components on collaborative innovation. European Management Review, 2012,9(2):85-98

Secchi, M., Castellani, V., Collina, E., et al. 2016. Assessing eco-innovations in green chemistry: Life cycle assessment (LCA) of a cosmetic product with a bio-based ingredient. Journal of Cleaner Production. 129:269-281

Song, M.L., Wang, S.H. 2013. Analysis of environmental regulation, technological progression and 

economic growth from the perspective of statistical test. Economic Research Journal. (3):122134

Song, M.L., Wang, S.H., Zhang, H.Y. 2020. Could environmental regulation and R\&D tax incentives affect green product innovation? Journal of Cleaner Production. 258:120849

Song M.L., Tao J., Wang S.H. 2015. FDI, technology spillovers and green innovation in China: analysis based on data envelopment analysis. Annals of Operations Research,228(1):47-64

Srivastava, M.K., Gnyawal, D.R. 2017. When do relational resources matter? Leveraging Portfolio Technological Resources for Breakthrough Innovation. IEEE Engineering Management Review. 45(2):83-96

Stucki, T., Woerter, M., Arvanitis, S., Peneder, M., et al. 2018. How different policy instruments affect green production innovation: a differentiated perspective. Energy Policy, 114:245-261

Tong, Z and Ze, J. 2021. Corruption pays off: How environmental regulations promote corporate innovation in a developing country. Ecological Economics, 183:106969

Tsai, W., and Ghoshal,S. 1998. Social capital and value creation: the role of intrafirm networks. Academy of Management Journal, 41(4):464-476

Vasilenko, L.; Arbac`iauskas, V. Obstacles and Drivers for Sustainable Innovation Development and Implementation in Small and Medium Sized Enterprises. Environmental Research Engineering and Management. 2012, 60, 58-66.

Villegas-Palacio, C., Coria, J. 2010. On the interaction between imperfect compliance and technology adoption: taxes versus tradable emissions permits. Journal of Regulatory Economic, $38(3): 274-291$

Wang, F., Feng, L., Li, J., et al. 2020. Environmental regulation, tenure length of officials, and GI 
652

653

654

655

656

657

658

659

660

661

662

663

664

665

666

667

668

669

670

671

672

of enterprises. International Journal of Environmental Research and Public Health.17(7):2284

Wang, H.R., Cui, H.R., Zhao, Q.Z. 2021. Effect of green technology innovation on green total factor productivity in China: Evidence from spatial durbin model analysis. Journal of Cleaner Production, 288:125624

Wang, R.Q., Wang, F.J., Xu, L.Y., et al. 2017. R\&D expenditures, ultimate ownership and future performance: Evidence from China. Journal of Business Research, 71:47-54

West, J and Gallagher, S. 2006. Challenges of Open Innovation: The Paradox of Firm Investment in Open-source Software, R\&D Management,36(3):319-331

Xia, D., Chen, W.H., Gao, Q.L., et al. 2021. Research on enterprises' intention to adopt green technology imposed by environmental regulations with perspective of state ownership. Sustainability, 13(3):1368

Xin, J.Y., Yeung, A.C.L., Cheng, T.C.E. 2010. First to market: is technological innovation in new product development profitable in health care industries? International Journal of Production Economics, 127(1):129-135

Zhang, J.X., Ouyang, Y., Ballesteros-Perez, P., et al. 2021. Understanding the impact of environmental regulations on green technology innovation efficiency in the construction industry. Sustainable Cities and Society, 65:102647

Zhang, X.H., Tan, Z.D., Chang, B.G., et al. 2020. Is a regional coordination approach to air pollution management helpful? Evidence from China. Sustainability, 12(1):134

Zhou, Q., Zhong, S.H., Shi, T., et al. 2021. Environmental regulation and haze pollution: Neighborcompanion or neighbor-beggar? Energy Policy, 151:112183 
Table 1

2 Descriptive analysis $(\mathrm{N}=795)$

\begin{tabular}{|c|c|c|c|c|c|}
\hline Variables (Abbreviation) & Meaning & Mean & $\begin{array}{l}\text { Std. } \\
\text { Dev }\end{array}$ & Min & Max \\
\hline $\begin{array}{l}\text { Environmental governance } \\
(E G)\end{array}$ & Pollution treatment investment & 0.774 & 1.186 & 0.000 & 6.690 \\
\hline $\begin{array}{l}\text { Green technology innovation } \\
(G T I)\end{array}$ & Environmental Patent Application & 7.436 & 3.352 & 13.816 & 17.532 \\
\hline $\begin{array}{l}\text { Knowledge and Technology } \\
\text { Transfer }(K T T)\end{array}$ & Technology Patent disclosure/transfer & 0.502 & 0.500 & 0.000 & 1.000 \\
\hline Age of the enterprises $(A G E)$ & Years of establishment & 3.317 & 0.215 & 2.397 & 3.689 \\
\hline Current ratio $(C R)$ & Ratio of current assets to current liabilities & 4.877 & 0.610 & 2.865 & 7.994 \\
\hline Return on assets $(R O A)$ & $\begin{array}{l}\text { Ratio of net profit to annual average total } \\
\text { assets }\end{array}$ & 5.323 & 0.139 & 2.577 & 5.533 \\
\hline Asset turnover rate $(A T R)$ & $\begin{array}{l}\text { Ratio of business income to annual average } \\
\text { total assets }\end{array}$ & 4.158 & 0.576 & 1.556 & 5.748 \\
\hline Ownership structure $(O S)$ & $\begin{array}{l}\text { The state-owned enterprises equal to } 1 \text {, } \\
\text { otherwise equal to } 0 \text {. }\end{array}$ & 0.697 & 0.460 & 0.000 & 1.000 \\
\hline
\end{tabular}

4 Table 2

5 Correlation analysis

\begin{tabular}{|c|c|c|c|c|c|c|c|c|}
\hline Variables & $G T I$ & $E R$ & $K T T$ & $A G E$ & $C R$ & $R O A$ & ATR & $O S$ \\
\hline$G T I$ & 1.000 & & & & & & & \\
\hline$E R$ & $0.146^{* * *}$ & 1.000 & & & & & & \\
\hline KTT & $0.415^{* * *}$ & $0.069^{* *}$ & 1.000 & & & & & \\
\hline$A G E$ & 0.008 & -0.026 & -0.013 & 1.000 & & & & \\
\hline$C R$ & $-0.127^{* * *}$ & $-0.244^{* * *}$ & $-0.154^{* * *}$ & 0.026 & 1.000 & & & \\
\hline$R O A$ & $0.058^{*}$ & 0.018 & $0.091^{* * *}$ & -0.003 & $0.213^{* * *}$ & 1.000 & & \\
\hline$A T R$ & $0.121^{* * *}$ & $0.068^{* *}$ & $0.165^{* * *}$ & 0.052 & 0.011 & $0.141^{* * *}$ & 1.000 & \\
\hline$O S$ & $0.060^{*}$ & $0.100^{* * *}$ & $0.121^{* * *}$ & $-0.115^{* * *}$ & $-0.174^{* * *}$ & $-0.121^{* * *}$ & 0.038 & 1.000 \\
\hline
\end{tabular}


Table 3

8 Regression results of benchmark effect of the EG on GTI

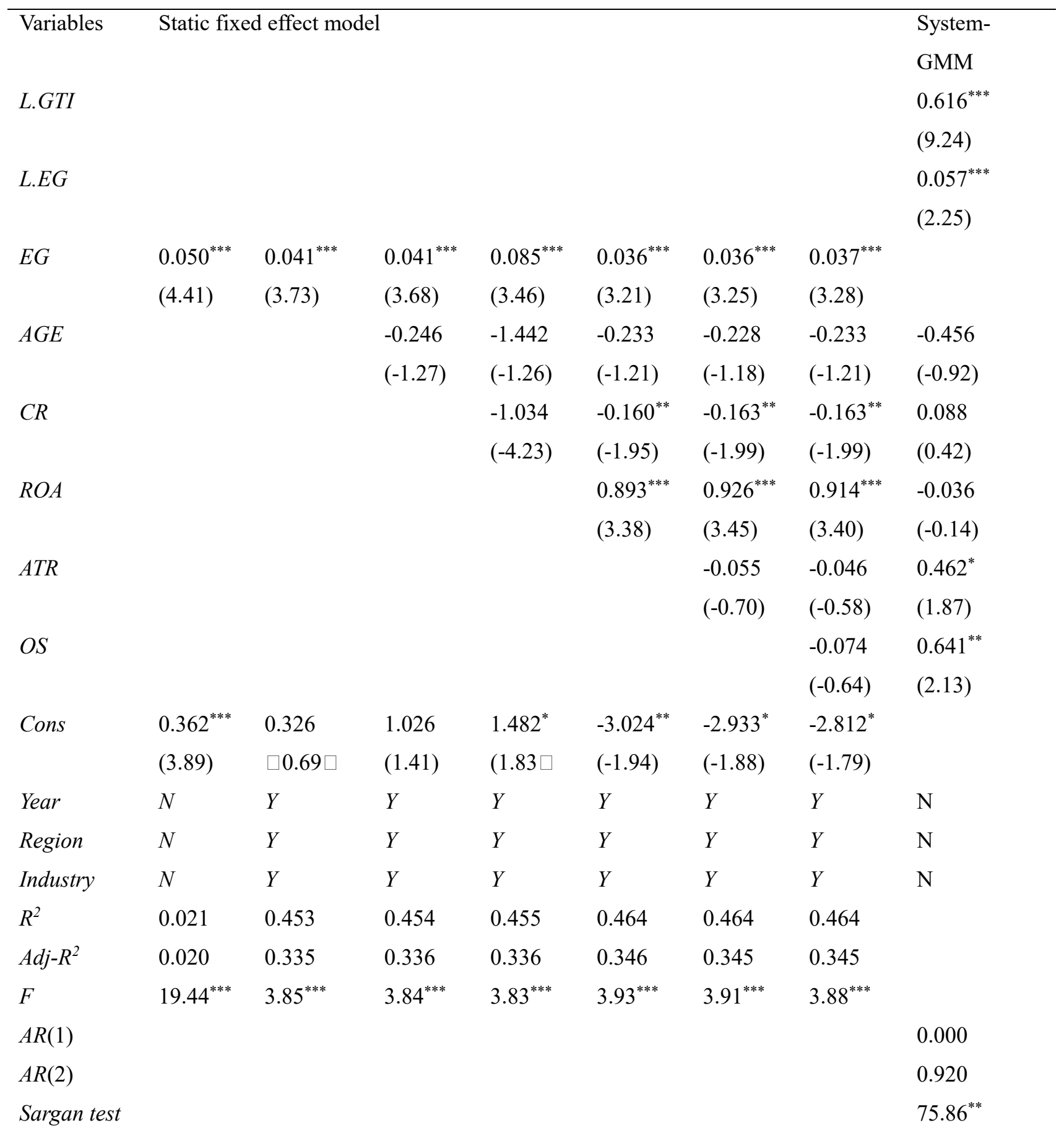

9 The numbers in parentheses are t-statistic; ${ }^{*} \mathrm{p}<0.1 .{ }^{* *} \mathrm{p}<0.05 .{ }^{* * *} \mathrm{p}<0.01$. 
Table 4

11 Heterogeneity regression results of $E G$ on $G T I$

\begin{tabular}{llll}
\hline Variables & Growth & Mature & Recession \\
\hline$E G$ & $0.053^{* *}$ & $0.089^{* * *}$ & 0.067 \\
& $(2.48)$ & $(3.07)$ & $(0.67)$ \\
$A G E$ & 0.112 & $-0.998^{*}$ & $-1.516^{* * *}$ \\
& $(0.32)$ & $(-1.74)$ & $(-3.60)$ \\
$C R$ & -0.112 & $-0.723^{* * *}$ & $-0.314^{* *}$ \\
& $(-0.63)$ & $(-2.80)$ & $(-1.69)$ \\
ROA & $0.700^{*}$ & 0.232 & $0.185^{* *}$ \\
& $(1.66)$ & $(1.59)$ & $(2.33)$ \\
ATR & -0.058 & 0.025 & $0.326^{*}$ \\
& $(-0.36)$ & $(0.11)$ & $(1.79)$ \\
OS & -0.208 & 0.132 & -0.172 \\
& $(-0.96)$ & $(0.35)$ & $(-0.72)$ \\
Year & $\mathrm{Y}$ & $\mathrm{Y}$ & $\mathrm{Y}$ \\
Region & $\mathrm{Y}$ & $\mathrm{Y}$ & $\mathrm{Y}$ \\
Industry & $\mathrm{Y}$ & $\mathrm{Y}$ & $\mathrm{Y}$ \\
$R^{2}$ & 0.497 & 0.793 & 0.711 \\
Adj- $R^{2}$ & 0.235 & 0.638 & 0.591 \\
$F$ & $1.90^{* * *}$ & $5.11^{* * *}$ & $5.91^{* * *}$ \\
\hline Then & & $\mathrm{p}$ &
\end{tabular}

12 The numbers in parentheses are t-statistic; ${ }^{*} \mathrm{p}<0.1 .{ }^{* *} \mathrm{p}<0.05 .{ }^{* * *} \mathrm{p}<0.01$. 
13 Table 5

14 Mediation effect result of KTT on the relationship between $E G$ and GTI

\begin{tabular}{lll}
\hline Variables & Static fixed effect model \\
L.GTI & & \\
& & \\
$E G$ & $-0.032^{* *}$ & $-0.031^{* *}$ \\
& $(-2.49)$ & $(-2.24)$ \\
$E G^{*} K T T$ & $0.120^{* * *}$ & $0.096^{* * *}$ \\
& $(12.73)$ & $(9.15)$
\end{tabular}

L.EG

L.EG*KTT

$0.032^{* *}$

(1.74)

$A G E$

$-0.144$

0.506

$(-0.69)$

(1.00)

$S O L$

$-0.144^{*}$

$0.736^{* * *}$

$(-1.77)$

(3.75)

$R O A$

$0.753^{* * *}$

$-0.414^{* * *}$

(2.89)

$(-2.84)$

ATR

$-0.116$

$-0.194$

$(-1.36)$

$(-1.08)$

$O S$

$-0.127$

$-0.217$

$(-1.06)$

$(-0.81)$

Year N

$\mathrm{Y}$

$\mathrm{N}$

Region

$\mathrm{N}$

Industry

$\mathrm{N}$

$\mathrm{Y}$

$\mathrm{N}$

$\mathrm{Y}$

$\mathrm{N}$

$R^{2}$

0.188

0.536

$\operatorname{Adj-R^{2}}$

0.186

0.422

$F$

$91.50^{* * *}$

$4.71^{* * *}$

$A R(1)$

0.089

$A R(2)$

0.509

Sargan test

$109.86^{* * *}$

15 The numbers in parentheses are t-statistic; ${ }^{*} \mathrm{p}<0.1 .{ }^{* *} \mathrm{p}<0.05 .{ }^{* * *} \mathrm{p}<0.01$. 
0.900

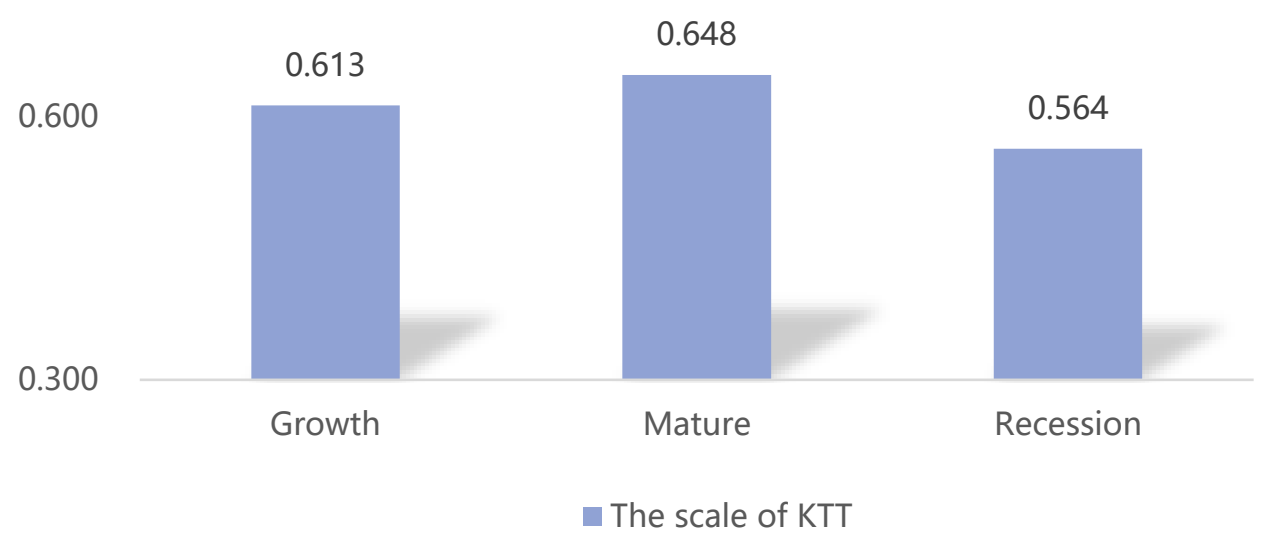

1

Figure.1 Difference of the scale of KTT in different life cycle stage 


\section{Highlights}

1. Takes enterprise's life cycle stage as the breakthrough point, this paper analyzes the dynamic effect of environment governance on green technology innovation.

2. The effect of environment governance on green technology innovation of enterprises with different life cycle is different.

3. Knowledge and technology transfer in growth and mature stage is significantly better than that of enterprises in recession

4. Knowledge and technology transfer have a positive moderating effect on the relationship between environment governance and green technology innovation. 